\title{
Electrocardiograms in Acute Pericarditis
}

\author{
Anita Radhakrishnan and Jerome E. Granato \\ Department of Medicine and Division of Cardiology \\ West Penn Allegheny Health System, Pittsburgh \\ USA
}

\section{Introduction}

The pericardium surrounds the heart and consists of a visceral layer, which is contiguous with the epicardium of the heart, and a parietal layer, which forms a sac around the heart (Wann \& Passen, 2008). Located between the parietal and visceral layers is a potential space called the pericardial cavity. The pericardial cavity normally contains as much as $50 \mathrm{~mL}$ of an ultrafiltrate of plasma. Anatomically, the pericardium isolates the heart from the rest of the mediastinum and thorax. Physiologically and under normal circumstances, the pericardium may have little if any significant role. The pericardial structure and function may be impacted by numerous pathologic conditions. Many of these conditions are listed in Table 1. A common and nonspecific condition affecting the pericardium is acute pericarditis. Acute pericarditis is a clinical syndrome that may present with chest pain, a pericardial friction rub, and gradual repolarization changes in the electrocardiogram (ECG). The diagnosis of acute pericarditis requires at least 2 of these 3 elements (Imazio et al, 2003)

\section{Etiology of acute pericarditis}

\begin{tabular}{|l|l|l|}
\hline Infectious & Viral & $\begin{array}{l}\text { Cocksacie A \& B, Echovirus, } \\
\text { Adenovirus, Mumps, Hepatitis, HIV }\end{array}$ \\
\hline & Pyogenic & $\begin{array}{l}\text { Pneumococcus, Streptococcus, } \\
\text { Staphylococcus, Neisseria and } \\
\text { Legionella }\end{array}$ \\
\hline & Fungal & Histoplasmosis, Coccidiomycosis \\
\hline Metabolic & Other & $\begin{array}{l}\text { Tuberculous, Syphilitic, Protozoal and } \\
\text { Parasitic }\end{array}$ \\
\hline Neoplasm & Uremia/ Dialysis & \multicolumn{2}{|l|}{} \\
\hline Trauma & Hypothyroidism & $\begin{array}{l}\text { Primary tumors or tumors metastatic to } \\
\text { the pericardium (lung, breast, } \\
\text { lymphoma, and leukemia) }\end{array}$ \\
\hline Tumors & $\begin{array}{l}\text { Penetrating/Non-penetrating chest wall } \\
\text { Post-irradiation, Post thoracic surgery, } \\
\text { catheter or pacemaker perforation }\end{array}$ \\
\hline
\end{tabular}




\begin{tabular}{|c|c|c|}
\hline Autoimmune & Sarcoidosis & \\
\hline & $\begin{array}{l}\text { Collagen Vascular } \\
\text { Disorders }\end{array}$ & $\begin{array}{l}\text { SLE, Rheumatoid Arthritis, Ankylosing } \\
\text { Spondylitis, Scleroderma, Wegeners, } \\
\text { Rheumatic Fever }\end{array}$ \\
\hline Hypersensitivity & Drug Induced & $\begin{array}{l}\text { Procainamide, Hydralazine, Phenytoin, } \\
\text { INH, Minoxidil, Methysergide, } \\
\text { Anticoagulation }\end{array}$ \\
\hline \multirow[t]{5}{*}{ Others } & $\begin{array}{l}\text { Acute Myocardial } \\
\text { Infarction }\end{array}$ & Dresslers Pericarditis \\
\hline & Aortic dissection & With leakage into the pericardial sac \\
\hline & IBD & \\
\hline & Syndromes & Loefflers Syndrome /Whipples Disease \\
\hline & Familial & $\begin{array}{l}\text { Familial Mediterranean Fever/Familial } \\
\text { Pericarditis }\end{array}$ \\
\hline
\end{tabular}

Table 1. Causes of acute pericarditis (Zayas et al, 1995)

\section{Clinical features}

The chest pain associated with acute pericarditis is often described as severe, retrosternal, left sided precordial pain that is referred to the neck, arms, or the left shoulder. The pain is usually pleuritic, consequent to accompanying pleural inflammation and is characteristically, relieved by sitting up, leaning forward and may be intensified by lying supine (Troughten et al, 2004). The most specific sign of acute pericarditis is a pericardial friction rub, although it is intermittently present and often varies in intensity. It is characterized as a high-pitched scratchy sound and is heard best in end expiration and along the left sternal border with the patient leaning forward. A triple cadence is classically described, which coincides with atrial systole, ventricular systole, and rapid ventricular filling during early diastole. However, the triphasic rub occurs in only about half of patients. The origin of the sound has been attributed to the visceral and parietal layers of the pericardial sac rubbing together during different phases of the cardiac cycle (Spodick, 1975).

\section{Diagnosis}

\subsection{Serum boimarkers}

Laboratory testing for acute pericarditis is nonspecific and provides limited guidance in determining a cause. White blood cell count, erythrocyte sedimentation rate, and serum Creactive protein level are modestly elevated in acute pericarditis regardless of the etiology. Surprisingly, a significant number of patients with pericarditis, with or without myocarditis or myocardial infarction have elevated creatinine kinase MB fraction and or troponin I values. This observation suggests that there is a significant incidence of silent myocarditis in patients who present with acute pericarditis (Imazio et al, 2003). If a particular etiology for pericarditis is suspected, the clinical presentation and associated co-morbid conditions should direct decisions for additional laboratory studies, such as rheumatoid factor, cardiac enzymes, antinuclear antibodies, or sputum samples to assess for mycobacteria. 


\subsection{Electrocardiography}

The ECG is a rapid, inexpensive and noninvasive test that can be very useful in establishing the diagnosis of acute pericarditis. In one study, $90 \%$ of patients with the diagnosis of acute pericarditis are found to have ECG changes (Marinella, 1998). The electrocardiogaphic patterns of acute pericarditis were first reported in 1929 by Scott, Feil and Katz. They described transitory elevation of the ST segments in all three limb leads of the electrocardiogram in a case of hemopericardium and in one of purulent pericarditis (Veer and Norris 1937). Since then, the diagnosis of pericarditis is often times made with ECG changes.

In acute pericarditis, the observed electrocardiographic changes are a direct result of the inflammatory process taking place between the pericardial layers. The electrocardiogram is altered because of the extension of the inflammatory process to the sub epicardial myocardium (Bonow et al, 2008). The two classical ECG findings of acute pericarditis are ST elevation and PR depression. Elevation of the ST segment is the most sensitive and most consistent ECG finding. Typically the ST elevation is usually $1.0-2.0 \mathrm{~mm}$ and may be present in the majority of the standard ECG leads. The exception to this observation may be seen in leads AVR and V1 where the ST segment is always depressed (Koos et al, 2009). The morphology of the ST segment elevation in acute pericarditis is characteristically concave

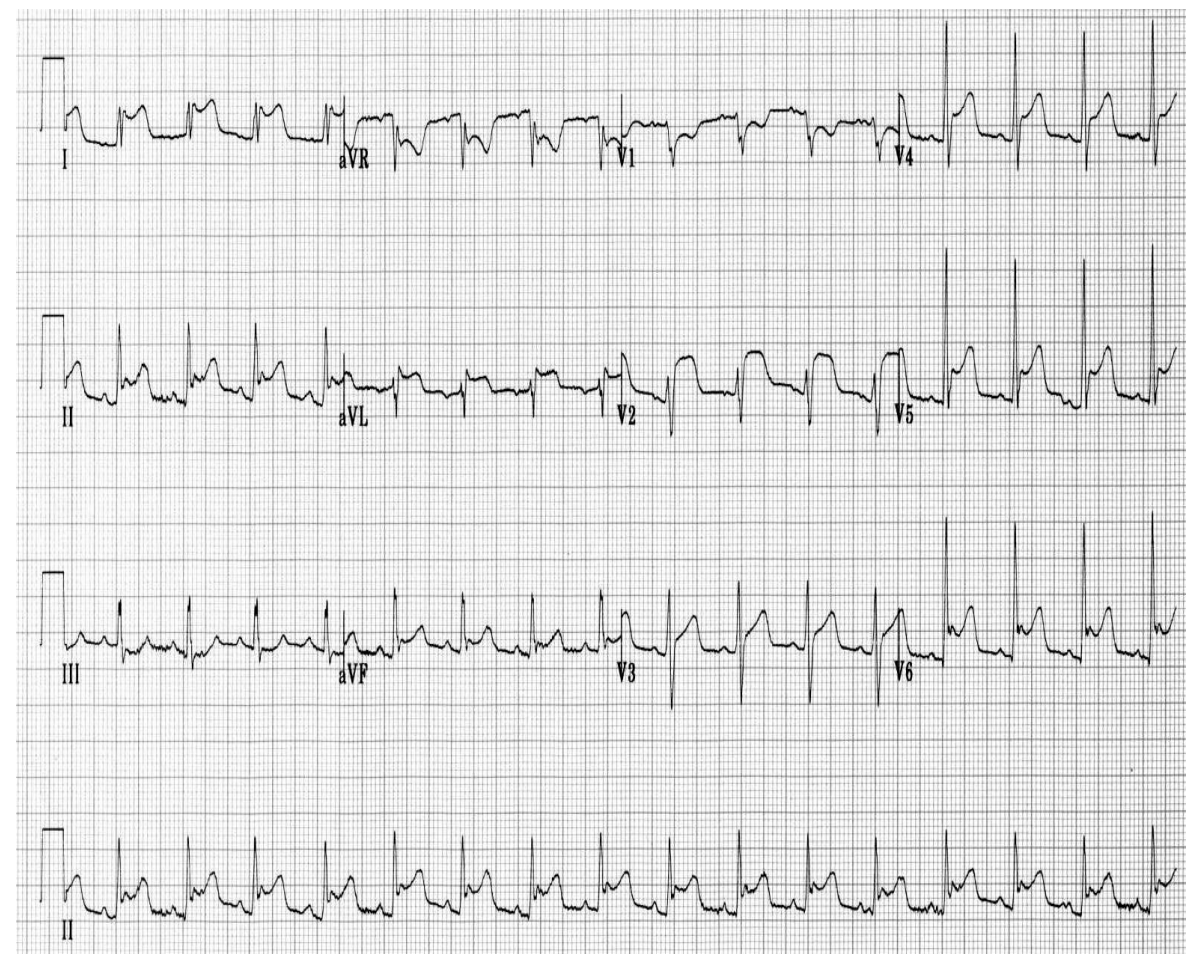

Fig. 1. An electrocardiogram in acute pericarditis showing diffuse up sloping ST segment elevations seen best here in leads II, AVL, AVF and V2 to V6. There is also subtle PR segment deviation (positive in aVR, negative in most other leads) (Hewitt el al, 2010) 
and facing upwards. Some causes of pericarditis do not result in significant inflammation of the epicardium and may not be associated with the typical ECG changes. An illustration of this is uremic pericarditis, in which there is prominent fibrin deposition but little or no epicardial inflammation. As a result, the ECG usually does not exhibit the previously described ECG changes (Rutsky \& Rostand, 1989). The ST segment elevations observed with acute pericarditis are often transient and are sometimes followed (after a variable time) by diffuses $\mathrm{T}$ wave inversions. The $\mathrm{T}$ wave inversions are also transient and may resolve completely with time (Maisch et al, 2004). Accordingly, there are some patients with clinical signs and symptoms of pericarditis, yet have a normal or non specific pattern on ECG. In the majority of patients, however, some electrocardiographic abnormality persists for an extended period of time. This is usually in the form of persistent $\mathrm{T}$ wave inversion (especially chronic pericarditis syndromes) (Maisch et al, 2004). The PR segment depression is another electrocardiographic sign of acute pericarditis. It is a very specific sign and is attributed to subepicardial atrial injury and is visible in all leads except aVR and V1. Conversely, these leads may exhibit PR-segment elevation as a manifestation of atrial wall inflammation (Hurst 2006). Thus, in acute pericarditis, the PR and ST segments typically change in opposite directions.

In acute pericarditis, the observed ECG changes typically evolve in four stages. Although all cases of pericarditis may not include each of these stages, as many as 50\% do (Spodick, 2003). The typical evolution of ECG changes in pericarditis is described below in Tables 2-5.

\begin{tabular}{|l|l|l|l|}
\hline Stage & $\begin{array}{l}\text { Time of } \\
\text { Onset }\end{array}$ & Classical ECG Findings \\
\hline Stage 1 1 & $\begin{array}{l}\text { Hours to } \\
\text { days }\end{array}$ & $\begin{array}{l}\text { Diffuse concave ST elevation } \\
\text { with reciprocal ST depression } \\
\text { in AVR and V1 } \\
\text { PR segment elevation in lead } \\
\text { AVR } \\
\text { Depression of the PR segment } \\
\text { in all other limb leads }\end{array}$ \\
\hline
\end{tabular}

Table 2. Stage 1 of pericarditis

\begin{tabular}{|l|l|l|l|}
\hline Stage & $\begin{array}{l}\text { Time of } \\
\text { Onset }\end{array}$ & Classical ECG findings & Illustration \\
\hline Stage 2 & $\begin{array}{l}\text { Within 1st } \\
\text { week }\end{array}$ & $\begin{array}{l}\text { Normalization of ST } \\
\text { segments, with J point } \\
\text { returning to normal } \\
\text { T wave amplitude begin to } \\
\text { decrease }\end{array}$ & Stage II \\
\hline
\end{tabular}

Table 3. Stage 2 of pericarditis 


\begin{tabular}{|l|l|l|l|}
\hline Stage & $\begin{array}{l}\text { Time of } \\
\text { Onset }\end{array}$ & Classic ECG Finding & Illustration \\
\hline Stage 3 & 2-3 Weeks & $\begin{array}{l}\text { Diffuse T wave } \\
\text { inversions, generally } \\
\text { after the ST segments } \\
\text { have become isoelectric }\end{array}$ & Stage III \\
\hline
\end{tabular}

Table 4. Stage 3 of pericarditis

\begin{tabular}{|l|l|l|l|}
\hline Stage & $\begin{array}{l}\text { Time of } \\
\text { Onset }\end{array}$ & Classic ECG Finding & Illustration \\
\hline Stage 4 & Up to 3 & $\bullet \begin{array}{l}\text { Normalization of the } \\
\text { ECG or } \\
\text { Indefinite persistence of } \\
\text { T wave inversions } \\
\text { ("chronic" pericarditis) }\end{array}$ & Stage IV \\
\hline
\end{tabular}

Table 5. Stage 4 of pericarditis

The ECG findings of acute pericarditis can often times be both subtle and confusing. In evaluating patients with chest discomfort and an abnormal ECG, there are other conditions that may mimic acute pericarditis and must be considered as well. These include an acute myocardial infarction and the early pattern of repolarization. Table 6 lists useful clues in differentiating acute pericarditis from these conditions.

While both acute pericarditis and acute myocardial infarction can present with chest pain and elevations in cardiac biomarkers, the electrocardiographic changes in acute pericarditis differ from those in ST elevation myocardial infarctions ( STEMI) in several ways.

- Morphology - The ST segment elevation in acute pericarditis begins at the J point, which represents the junction between the end of the QRS complex and the beginning of the ST segment. The ST segment elevation rarely exceeds $5 \mathrm{~mm}$, and usually retains its normal concavity. In contrast the typical finding in a STEMI presentation is convex (dome-shaped) ST elevation that may be more than $5 \mathrm{~mm}$ in height (Surawicz \& Knilans, 2008).

- Distribution - ST segment elevations in infarction are characteristically limited to anatomical groupings of leads that correspond to the localized vascular area of the infarct (anteroseptal and anterior leads V1 to V4; lateral leads I, aVL, V5, V6; inferior leads II, III, aVF). The pericardium envelops the heart therefore the ST changes are more generalized and typically are present in most leads in pericarditis.

- Reciprocal changes - STEMI is often associated with reciprocal ST segment changes, which are not seen with pericarditis except in leads aVR and V1. 


\begin{tabular}{|l|l|l|l|}
\hline ECG Findings & Acute Pericarditis & Myocardial Infarction & Early Repolarization \\
\hline $\begin{array}{l}\text { ST Segment } \\
\text { Change }\end{array}$ & Concave upward & Convex upward & Concave upward \\
\hline Q waves & Absent & Present & Absent \\
\hline $\begin{array}{l}\text { Reciprocal ST } \\
\text { changes }\end{array}$ & Absent & Present & Absent \\
\hline $\begin{array}{l}\text { Location of ST } \\
\text { elevation }\end{array}$ & $\begin{array}{l}\text { Limb and precordial } \\
\text { leads }\end{array}$ & Area of involved artery & Precordial Leads \\
\hline $\begin{array}{l}\text { ST/T ratio in } \\
\text { lead V6 }\end{array}$ & $>0.25$ & N/A & Absent \\
\hline $\begin{array}{l}\text { Loss of R wave } \\
\text { voltage }\end{array}$ & Absent & Present & Absent \\
\hline $\begin{array}{l}\text { PR segment } \\
\text { depression }\end{array}$ & Present & & \\
\hline $\begin{array}{l}\text { Illustrative } \\
\text { Example }\end{array}$ & & & \\
\hline
\end{tabular}

Table 6. A comparison of ECG's in acute pericarditis, acute myocardial infarction and early repolarization.

- Concurrent ST and T wave changes - ST segment elevation and T wave inversions do not generally occur simultaneously in pericarditis, while they commonly coexist in a STEMI. Peaked T waves (>10 mm high in precordial leads, $>5 \mathrm{~mm}$ high in limb leads), can be seen in STEMI but are not typical of pericarditis (Surawicz \& Knilans, 2008).

- $Q$ waves - Pathologic $Q$ waves, which may occur with extensive injury in STEMI, are generally not seen in pericarditis. The abnormal $\mathrm{Q}$ waves in MI reflect the loss of positive depolarization voltages because of transmural myocardial necrosis. Pericarditis, on the other hand, generally causes only superficial inflammation. Abnormal $Q$ waves are not seen unless there is concomitant myocarditis or preexisting cardiomyopathy or myocardial infarction (Imazio, 2011).

- $\quad$ PR segment - PR elevation in aVR with PR depression in other leads due to a concomitant atrial current of injury is frequently seen in acute pericarditis but rarely seen in acute STEMI.

- QT prolongation - Prolongation of the QT interval with regional T wave inversion (in the absence of drug effects or relevant metabolic disorders) favors the diagnosis of myocardial ischemia (or myopericarditis) over pericarditis alone (Marinella, 2008). 
The early repolarization variant seen on an ECG may be present in as many as 30\% of young adults and is often confused with acute pericarditis (Klatskey et al, 2003). The following electrocardiographic features can be helpful in distinguishing acute pericarditis from early repolarization:

- ST elevations occur in both the limb and precordial leads in most cases of acute pericarditis (47 of 48 in one study), whereas about one-half of subjects with early repolarization have no ST deviations in the limb leads. In early repolarization, ST elevation is most often present in the anterior and lateral chest leads (V3-V6), although other leads can be involved ( Spodick, 1976).

- PR deviation and evolution of the ST and T changes strongly favor pericarditis, as neither is seen in early repolarization( Ginzton \& Laks, 1972)

While uncommon, one of the most feared seqealae of acute pericarditis is the progression to cardiac tamponade. Cardiac tamponade is the result of the accumulation of fluid in the pericardial space to the point that it causes obstruction to the inflow of blood to the heart. This condition, if not recognized and treated promptly, is often fatal. The most common ECG sign of a large pericardial effusion is low voltage of the QRS complexes. This finding is most likely due to the attenuation of cardiac potentials caused by the fluid surrounding the heart as well as inflammatory mechanisms affecting the pericardium and myocardium (Brusch et al, 2001). Low voltage on the ECG (Figure 2) is said to be present when the cumulative amplitude of the QRS complexes in each of the six limb leads is $5 \mathrm{~mm}(0.5 \mathrm{mV})$ or less (Luenn et al, 2006). Another ECG pattern that may be observed in patients with a large pericardial effusion is total electrical alternans (Figure 3). The pattern of electrical alternans is characterized by a cyclic beat-to-beat variation in the QRS axis in the limb and precordial leads. This is a direct result of the beat to beat movement of the heart, both to and fro, that can occur in the presence of a large pericardial effusion (Billakanty and Bashir, 2006). The observations of electrical alternans with low QRS voltage and sinus tachycardia is a highly specific sign of pericardial effusion. Unfortunately, this triad of observations is only modestly sensitive in that there may be situation where larger pericardial effusion is present and some or all of these findings are absent.

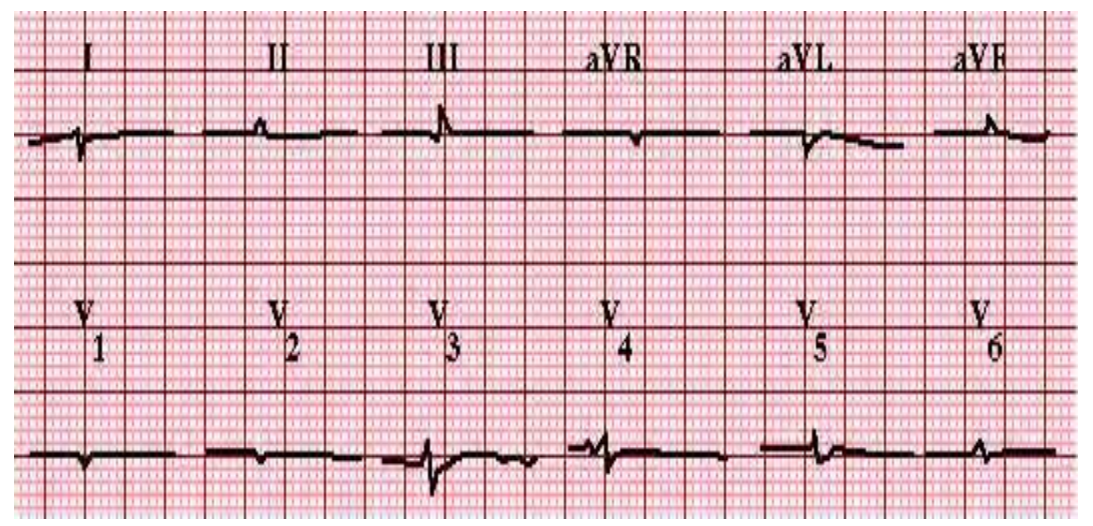

Fig. 2. An ECG in a patient with a large pericardial effusion. Note the presence of low voltage QRS in all leads. 


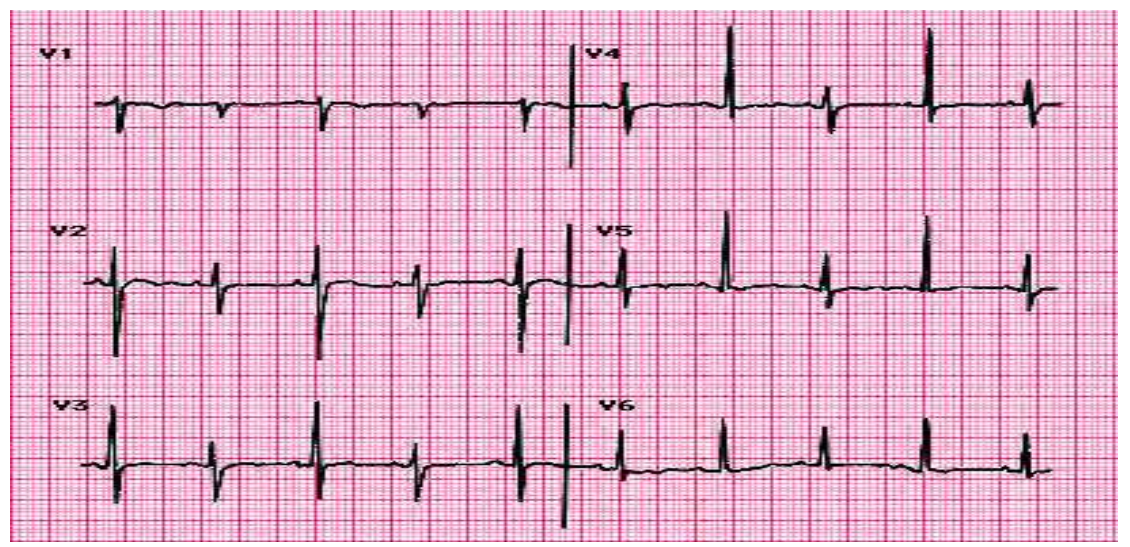

Fig. 3. An ECG in a patient with a large pericardial effusion. Note the alternating QRS axis in all precordial leads.

\subsection{Chest radiograph}

The chest radiograph is usually normal in uncomplicated acute idiopathic pericarditis. It is frequently useful to exclude pathology in the mediastinum or lung fields that may be the cause of pericarditis, such as thoracic malignancy or infection. A pericardial effusion should be suspected when cardiomegaly is observed and the cardiac silhouette takes on a symmetric "flask like" appearance, shown in Figure 4. (Spodick, 2003).

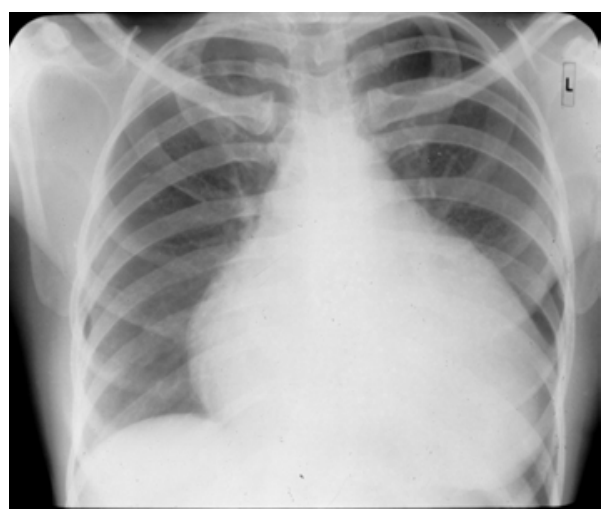

Fig. 4. Chest $X$ ray suggestive of a large pericardial effusion.

\subsection{Echocardiography}

The transthoracic echocardiography (TTE) is frequently normal in patients with acute idiopathic pericarditis. The main reason for its performance is for assessing the size and nature of any associated pericardial effusion. The observation of fibrin strand within the pericardial effusion is indicative of a pericardial inflammatory response (Verhaert et al, 2010). Transthoracic echocardiography is also essential in evaluating for presence or absence cardiac tamponade. This physiologic condition may be recognized by collapse of the right 
atrium or right ventricle during diastole or marked variation in the transmitral and transpulmonary valve velocity profiled with respiration (Fowler 1993). In one series of 300 consecutive patients with acute pericarditis, pericardial effusion was present in 180 patients $(60 \%)$. In most cases the effusion was small or moderate in size without hemodynamic consequences. Cardiac tamponade was present in only 5\% of patients (Imazio et al, 2004). TTE is not needed in every patient with pericarditis, it is recommended in patients with clinical features that would suggest the presence of a systemic disorder. These might include prolonged fever, an immunocompromised state, recent trauma, elevation of cardiac enzymes greater than 2 weeks, and abnormal chest $x$-ray or clinical signs of cardiac tamponade. (Imazio et al, 2004, 2007)

\subsection{CT/MRI}

The presence of pericardial fluid or thickening may be confirmed by a CT or MRI scan. These techniques may be superior to echocardiography in detecting loculated pericardial effusions, pericardial thickening presence of pericardial masses or any associated intrathoracic pathology (Verhaert et al, 2010). Neither CT nor MRI scanning however is needed to establish the diagnosis of pericarditis. Rather, these studies are generally reserved the evaluation of other pathologic conditions which may be the cause of pericarditis.

\section{Treatment}

The foundation of treatment for pericarditis is to reduce and ultimately eliminate the inflammatory process that exists between the pericardial layers. For patients with idiopathic pericarditis, nonsteroidal anti-inflammatory drugs (NSAIDs) should be used with the goal of relieving chest pain, inflammation, and fever. Aspirin, ibuprofen, and indomethacin are the most commonly prescribed NSAIDs. Ibuprofen may be preferred given its reportedly lower incidence of side effects compared to the other medications. (Zayas et al, 1995) Indomethacin is an acceptable alternative, but it should be avoided in patients with coronary artery disease because of its adverse effects on coronary blood flow and blood pressure (Maisch et al, 2004). Aspirin is favored in patients with a recent history of myocardial infarction since other NSAIDs tend to impede scar formation (Hammerman et al, 1984). The use of NSAIDs in the setting of acute myocardial infarction has been associated with an increased incidence of ventricular aneurysm formation and cardiac rupture (Imazio et al, 2004). Patients who respond slowly or inadequately to NSAIDS may require supplementary narcotic analgesics and or a brief course of colchicine or steroids. In cases where the etiology of pericarditis has been identified, treatment should be focused on the underlying cause. For patients who have chronic kidney failure, increasing the frequency of dialysis usually results in improvement in the signs and symptoms of uremic pericarditis. Patients who have cancer may show some response to chemotherapy or radiation therapy. For purulent pericarditis related to a bacterial or fungal process, treatment consists of antimicrobials and surgical drainage of purulent material from the pericardium space. For patients with pericardial effusion causing a tamponade, drainage of the effusion is indicated. Needle pericardiocentesis, via a sub xiphoid approach, is effective in most medical patients with cardiac tamponade when the effusion is circumferential and moderately large (Imazio et al, 2007). 


\section{Follow-up}

Most cases of acute pericarditis subside within 2 weeks. In approximately $15 \%$ of cases, symptoms may recur (Marinella, 1998). This is particularly true if the pericarditis is related to an ongoing and underlying illness such as an autoimmune disease or uremia. Typically, physicians should schedule a follow-up visit with these patients two weeks after the onset of their illness unless additional symptoms or medication related problems intervene. An ECG should also be considered at four weeks, bearing in mind that residual T-wave inversion may be present for several weeks during stage III of acute pericarditis.

\section{Conclusion}

In conclusion, acute pericarditis can be caused by many underlying conditions. Acute pericarditis can be diagnosed clinically with when associated with chest pain, pericardial friction rub and typical ECG changes. The ECG changes associated with acute pericarditis have been described as evolving through four stages including PR segment depression, ST segment elevation, $\mathrm{T}$ wave inversion and eventual normalization. Certain features of the ECG can help in differentiate the diagnosis of pericarditis from acute myocardial infarction or early repolarization, though this differentiation may be difficult. Treatment should be focused on the relief of symptoms and specific to any underlying cause. For patients with idiopathic pericarditis, NSAIDs are typically most effective. The prognosis associated with acute pericarditis is very good. Prompt recognition and treatment of this condition may prevent its progression to more serious complications.

\section{Acknowledgments}

Words alone cannot express the thanks I owe to Chocku Radhakrishnan, my husband and Mrs. Valli Radhakrishnan, my mother-in-law for their encouragement, patience and support while I wrote this paper. I would like to express gratitude to my father Mr. Ramanathan Vairavan who has encouraged me to work hard and efficiently and has always had a special interest in my personal growth. And last but not least I would like to thank my mother, Mrs. Alagu Vairavan for reminding me everyday that her love is absolutely unconditional.

\section{References}

Billakanty Sreedhar, MD; Riyaz Bashir, MD Echocardiographic Demonstration of Electrical Alternans JAMA. 1976;235(1):39-41.

Bonow Robert, Mann Douglas, Libby Peter, and Zipes Douglas.(2008)

Braunwald's Heart Disease: A Textbook of Cardiovascular Medicine. Sunders 8th ed. 2008. Pages 1076-1078

Borys Surawicz, MD, MACC and Timothy Knilans, MD, (2008) Chou's Electrocardiography in Clinical Practice, 6th Edition, 2008 pages 235-236

Bruch C, Schmermund A, Dagres N, et al. Changes in QRS voltage in cardiac tamponade and pericardial effusion: reversibility after pericardiocentesis and after anti-inflammatory drug treatment. J Am Coll Cardiol 2001; 38:219.

Fowler No. Cardiac tamponade. (1993)A clinical or an echocardiographic diagnosis? Circulation, Vol 87, 1738-1741 
Ginzton LE, Laks MM. The differential diagnosis of acute pericarditis from the normal variant: new electrocardiographic criteria. Circulation 1982; 65:1004.

Hammerman H, Alker KJ, Schoen FJ, Kloner RA. Morphologic and functional effects of piroxicam on myocardial scar formation after coronary occlusion in dogs. Am J Cardiol 1984; 53:604.

Hurst J. Willis, MD, MACP. (2006) The Interpretation of Electrocardiograms: Pretense or a Well-Developed Skill? Cardiol Clin 24 (2006) 305-307

Imazio M, Demichelis B, Cecchi E, et al.(2003) Cardiac troponin I in acute pericarditis. J Am Coll Cardiol 2003; 42:2144.

Imazio M, Cecchi E, Demichelis B, et al. Indicators of poor prognosis of acute pericarditis. Circulation 2007; 115:2739.

Klatsky AL, Oehm R, Cooper RA, et al. The early repolarization normal variant electrocardiogram: correlates and consequences. Am J Med 2003; 115:171.

Koos R, Schröder J, Kühl HP. (2009)Acute viral pericarditis without typical electrocardiographic changes assessed by cardiac magnetic resonance imaging. Eur Heart J. 2009 Dec; 30(23):2844.

Luen James Yip Wei, MBBS, MRCP, Lim Yean Teng, MBBS, MRCP, Tan Huay Cheem, MBBS, M MED, Chia Boon Lock, MBBS, FRACPDiscordant Limb-Lead and Precordial-Lead QRS Voltages in Inferior Myocardial Infarction

Circulation. 2006;113:e866-e868.

Maisch B, Seferovic PM, Ristic AD, Erbel R, Rienmüller R, Adler Y, Tomkowski WZ, Thiene $\mathrm{G}$, Yacoub $\mathrm{MH}$. Guidelines on the diagnosis and management of pericardial diseases executive summary; the Task Force on the Diagnosis and Management of Pericardial Diseases of the European Society of Cardiology. Eur Heart J 2004; 25:587.

Marinella Mark, M.D,(1998) Electrocardiographic Manifestations and Differential Diagnosis of Acute Pericarditis American Family Physician Volume 14, Issue 1, July 1998, Pages 31-50

Rutsky, EA, Rostand, SG.(1989) Pericarditis in end-stage renal disease: Clinical characteristics and management. Semin Dialysis 1989; 2:25

Spodick DH. (1975) Pericardial rub. Prospective, Multiple observer investigation of pericardial friction in 100 patients. Am J Cardiol 1975; 35:357.

Spodick DH. Acute pericarditis: current concepts and practice. JAMA 2003; 289:1150.

Spodick DH. Differential characteristics of the electrocardiogram in early repolarization and acute pericarditis. N Engl J Med 1976; 295:523.

Troughton RW, Asher CR, Klein AL. ( 2004) Pericarditis. Lancet 2004; 363:717.

Veer, Joseph B. Vander M.D., Robert F. Norris M.D. (1937) The electrocardiographic changes in acute pericarditis: A clinical and pathological study. American Heart Journal. Volume 14, Issue 1, July 1937, Pages 31-50

Verhaert David, MD, Ruvin S. Gabriel, MBChB, The Role of Multimodality Imaging in the Management of Pericardial Disease Circulation: Cardiovascular Imaging. 2010; 3: 333-343

Wann Samuel, Edward Passen. (2008) Echocardiography in Pericardial Disease. Journal of the American Society of Echocardiography. Volume 21, Issue 1, Pages 7-13. 
Zayas R, Anguita M, Torres F, et al. (1993) Incidence of specific etiology and role of methods for specific etiologic diagnosis of primary acute pericarditis. Am J Cardiol 1995; 75:378. 


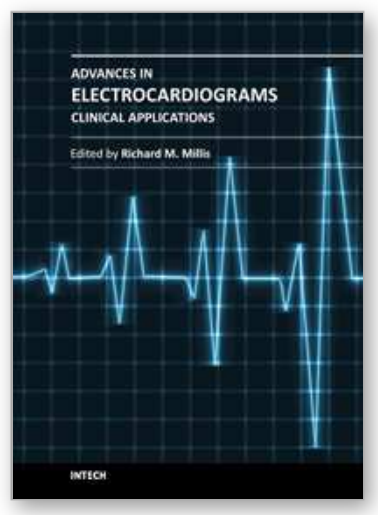

\author{
Advances in Electrocardiograms - Clinical Applications \\ Edited by PhD. Richard Millis
}

ISBN 978-953-307-902-8

Hard cover, 328 pages

Publisher InTech

Published online 25, January, 2012

Published in print edition January, 2012

Electrocardiograms have become one of the most important, and widely used medical tools for diagnosing diseases such as cardiac arrhythmias, conduction disorders, electrolyte imbalances, hypertension, coronary artery disease and myocardial infarction. This book reviews recent advancements in electrocardiography. The four sections of this volume, Cardiac Arrhythmias, Myocardial Infarction, Autonomic Dysregulation and Cardiotoxicology, provide comprehensive reviews of advancements in the clinical applications of electrocardiograms. This book is replete with diagrams, recordings, flow diagrams and algorithms which demonstrate the possible future direction for applying electrocardiography to evaluating the development and progression of cardiac diseases. The chapters in this book describe a number of unique features of electrocardiograms in adult and pediatric patient populations with predilections for cardiac arrhythmias and other electrical abnormalities associated with hypertension, coronary artery disease, myocardial infarction, sleep apnea syndromes, pericarditides, cardiomyopathies and cardiotoxicities, as well as innovative interpretations of electrocardiograms during exercise testing and electrical pacing.

\title{
How to reference
}

In order to correctly reference this scholarly work, feel free to copy and paste the following:

Anita Radhakrishnan and Jerome E. Granato (2012). Electrocardiograms in Acute Pericarditis, Advances in Electrocardiograms - Clinical Applications, PhD. Richard Millis (Ed.), ISBN: 978-953-307-902-8, InTech, Available from: http://www.intechopen.com/books/advances-in-electrocardiograms-clinical-applications/acutepericarditis

\section{INTECH}

open science | open minds

\section{InTech Europe}

University Campus STeP Ri

Slavka Krautzeka 83/A

51000 Rijeka, Croatia

Phone: +385 (51) 770447

Fax: +385 (51) 686166

www.intechopen.com

\section{InTech China}

Unit 405, Office Block, Hotel Equatorial Shanghai

No.65, Yan An Road (West), Shanghai, 200040, China 中国上海市延安西路65号上海国际贵都大饭店办公楼405单元

Phone: +86-21-62489820

Fax: +86-21-62489821 
(C) 2012 The Author(s). Licensee IntechOpen. This is an open access article distributed under the terms of the Creative Commons Attribution 3.0 License, which permits unrestricted use, distribution, and reproduction in any medium, provided the original work is properly cited. 